\title{
Discurso, poder y legitimidad: los dispositivos del desarraigo (isla Mocha, 1684) ${ }^{1}$
}

Aceptación: Enero - 2008

Aprobación: Abril - 2008

\section{RESUMEN}

El peligro que representaron las incursiones de corsarios ingleses y holandeses en las aguas del océano Pacífico, determinó que la autoridad virreinal del Perú solicitara evaluar el traslado de los nativos de isla Mocha al continente. En 1684 se generó un debate que buscó crear un consenso de legitimidad para esta acción. Dos alternativas se barajaron para alcanzar este objetivo: una fallida estrategia judicial que pretendió demostrar que los indios habían incurrido en un acto de traición, y el manejo de los estereotipos relativos a la naturaleza de los indios. En ambas situaciones, el análisis del discurso revela la creación premeditada de un disputado espacio de poder.

PALABRAS CLAVE: isla Mocha, José de Garro, reche-mapuches, dispositivos de desarraigo.

\section{ABSTRACT}

The threat that represented the incursions of English and Dutch corsairs in the waters of the Pacific Ocean, determined that the Viceroy of Peru requested to assess the relocation of Mocha Island' natives to the mainland. In 1684 started a debate that sought to create a consensus of legitimacy for this action. Two alternatives were utilized to achieve this goal: a judicial argument that the Indians had engaged in an act of treason, a strategy that ultimately failed; and the deployment of stereotypes concerning the nature of the Indians. In both cases, the discourse analysis reveals the premeditated creation of a disputed area of power.

KEY WORDS: isla Mocha, José de Garro, reche-mapuches, attachment device.

1 Investigación financiada por la Dirección de Investigación de la Universidad de Chile, Proyecto DI Código SOC 05/12-2, titulado "De Insulares a Continentales: la historia de los mochanos, desde los orígenes hasta su desintegración social en la Misión de San José de la Mocha".

* Departamento de Ciencias Históricas, Universidad de Chile. Correo electrónico fgoicovi@uchile.cl 


\section{Introducción}

Ante la permanente amenaza de Inglaterra, Holanda y Francia -las potencias marítimas europeas que desde fines del siglo XVI y comienzos del XVII disputaban aventajadamente la primacía de la antaño poderosa España-, en carta de 7 de marzo de 1684 el entonces virrey del Perú, Duque de la Palata, informó al gobernador de Chile, José de Garro, de la preocupación que significaba para las autoridades virreinales la presencia creciente y sostenida de naves adversas a la monarquía ibérica en las aguas del Pacífico. Consciente, por una parte, de que los limitados medios materiales que podían transportar dichas embarcaciones de guerra exigían el aprovisionamiento en los territorios del Nuevo Mundo, así como de la potencial alianza con los naturales que aún no estaban sometidos a las normas de la política hispánica y la religión católica, el virrey manifestó la inquietud que representaba el hecho de que "en la isla de la Mocha y de Santa María, enfrente de la Concepción, a crecido tiento [tanto] aquel gentío que tiene muy cultivadas las tierras y con todos los bastimentos nezesarios que puede hazer apetecible el sitio a los enemigos de Europa para tomar pie y tener inquieta nuestra frontera"2. En efecto, la autoridad virreinal estaba consciente de que el escaso conocimiento de estos territorios por parte de los adversarios europeos, así como la necesidad de contar con aliados que reforzaran los exiguos y agotados contingentes que habían realizado la travesía marítima, obligaba a los invasores a diseñar esquemas de ocupación en los que, necesariamente, debía contarse con la ayuda de los habitantes originarios de estas latitudes: trasladar la guerra europea contra España a América requería de una alianza con los nativos (León 2000-2001: 109). El siguiente cuadro sintetiza las incursiones de los corsarios que después de atravesar el estrecho de Magallanes o el cabo de Hornos, asolaron las costas de Chile:

Desde las últimas décadas del siglo XVI, la atmósfera de inseguridad que provocaba la amenaza de ultramar, y que acongojaba los ánimos de los súbditos de la Casa de Austria que se asentaban en la capital del principal enclave político, económico y administrativo de la América hispana subecuatorial, quedó plasmada en numerosos documentos redactados por las autoridades virreinales. Hacia mediados de febrero de 1590, por ejemplo, don Fernando de Torres y Portugal, Conde del Villardompardo, aconsejó al rey la implementación de medidas "para que los enemigos no se atrevan a entrar en aquel mar por el estrecho y si alguno lo hiciera sea castigado, lo cual no sería de poco efecto y provecho" ${ }^{3}$.

\begin{tabular}{lcl}
\hline \multicolumn{1}{c}{ INGLESES } & AÑO & \multicolumn{1}{c}{ HOLANDESES } \\
\hline Francis Drake & 1578 & \\
Thomas Cavendish & 1587 & \\
Richard Hawkins & 1594 & \\
& 1599 & Simón de Cordes \\
& 1600 & Balthasar de Cordes \\
& 1600 & Olivier van Noorth \\
& 1615 & Jaris van Spilbergen \\
& 1616 & Jacobo Le Maire \\
& 1623 & Jilliam Schouten \\
& $1642-43$ & Hendrick Brouwer \\
John Narborough & 1669 & \\
\hline
\end{tabular}

Ya en la siguiente centuria don Francisco de Borja y Aragón, Príncipe de Esquilache, informó que apenas había asumido el gobierno se experimentó la amenaza de navíos holandeses en las costas de Chile, coyuntura que le permitió comprobar la falta de medios de defensa del virreinato, ya que halló "gran falta de galeones en la real armada"4. Casi tres lustros después, don Diego Fernández de Córdoba, Marqués de Guadalcázar, hacía ver que "antiguamente tuvieron muy corto estado las cosas de guerra en estas provincias [...]. Pero después que los ingleses dieron principio a entrar en este mar por el estrecho de Magallanes se fue viviendo con más cuidado en esta parte, y últimamente obligado a mucho el haber descubierto los holandeses otro

2 "Carta del Virrey del Perú, Duque de la Palata al Presidente de Chile, para que viese lo que podría ejecutarse acerca de la enseñanza religiosa de los indios de la Mocha; Lima, 7 de marzo de 1684", Biblioteca Nacional, Originales Medina (en adelante B.N.O.M.), t. 323, f. 412.

3 “Memoria gubernativa del Conde del Villardompardo, 1592-1593" (Hanke (t. 1) 1978: 241).

4 “Relación del Príncipe de Esquilache, 1621?” (Hanke (t. 2) 1978: 185). 
que ellos llaman de Maire" 5 . Suma y sigue. En 1640 don Luis Gerónimo Fernández de Cabrera y Bobadilla, Conde de Chinchón, insistía en la apreciación de su predecesor sobre las nefastas consecuencias que representaban los descubrimientos geográficos de pasos interoceánicos de parte de los holandeses para la seguridad de España en las Indias Occidentales; en la Relación de su gobierno indicó que hasta hace un tiempo "los riesgos y las ocasiones de entradas de corsarios en el mar del Sur eran raras. Mas después que se descubrió el estrecho de San Vicente, de Maire, o Los Nodales, aunque en mayor altura que del de Magallanes, por estarlo en 56 grados y medio, se facilitó la navegación; y las naciones del norte, particularmente holandeses, se alargan de suerte con osadía y atrevimiento, que eso obligó a mayor cuidado"'. Solo ocho años más tarde don Pedro de Toledo y Leiva, Marqués de Mancera, representó al rey la turbación que cundió cuando "sobrevino la entrada de los holandeses el año 1643, por mayo, con resolución de ejecutar la orden que traían del Príncipe de Orange, que después se averiguó que era de entrar en Valdivia y si no estaban allí los españoles, fortificar el puerto, confederarse con los indios y armarlos con gran suma de armas que traían" ". Un cuarto de siglo después, la Real Audiencia de Lima trazaba un cuadro similar de la situación, ya que "los enemigos de Europa trataban de invadir estas costas, y en especial al puerto de Valdivia, con número de bajeles, ordenando se estuviese con tan gran desvelo y prevención que moralmente se pudiese esperar que si ingleses $u$ otras naciones intentasen con cualquier pretexto entrar en aquella plaza y lograr sus malos designios, no solo fuesen rechazados sino que quedasen con escarmiento"8. El sucesor en el mando, don Baltasar de la Cueva Enríquez, Conde de Castellar, hizo una abreviada radiografía del ambiente de tensión que se vivía en el último tiempo, puesto que "desde que gobernó este reino el Sr. Virrey Conde de Santisteban, que hará 20 años, sucesivamente fueron repitiéndose diferentes cédulas de S.M. participando a este gobierno los recelos y noticias de las prevenciones de enemigos de Europa, con designios de pasar a este mar a infestarle con gruesa armada y hacer hostilidades en sus costas, ordenando el cuidado y prevenciones con que se había de resguardar su defensa" ${ }^{\text {. La }}$ relación de su sucesor, don Melchor de Liñán y Cisneros, tiene la particularidad de establecer una comparación entre las dos principales fuentes de inestabilidad que aquejaban a la Capitanía General de Chile, al indicar que en "lo que toca a la guerra de los indios infieles que confinan con los de paz, no hay por ahora de que hacer mucho caso pues contenidos dentro de sus términos, con no hacerles daño y estando a la mira y con cuidado los corregidores confinantes se remedia. El mayor cuidado viene a consistir en las invasiones e infestaciones que pueden hacer los ingleses y otros enemigos de la corona" ${ }^{10}$.

El balance de las sucesivas autoridades virreinales era del todo desalentador. La situación que se vivía en las posesiones más meridionales de la Corona española distaba considerablemente de lo que se podría esperar del que aún era el mayor imperio del globo: miedo, incertidumbre, y la permanente incapacidad de contrarrestar las embestidas de sus enemigos continentales, revelaban que el Siglo de Oro Español había llegado a su fin. Las riquezas y situación estratégica de las posesiones americanas despertó en los ingleses un vivo interés en establecer un puesto de avanzada en el estrecho de Magallanes, mientras que los holandeses, sus inmediatos sucesores, desde los albores del sigo XVII asolaron las costas del Pacífico meridional con claras pretensiones de conquista (Stewart 2000: 124).

5 “Razón del estado en que el Marqués de Guadalcázar deja el gobierno del Perú al Virrey Conde de Chinchón, 14 de Diciembre de 1628" (Hanke (t. 2) 1978: 269).

6 “Relación del Estado en que el Conde de Chinchón deja el gobierno del Perú al Marqués de Mancera, 26 de enero de 1640 ” (Hanke (t. 3) 1978: 73).

7 "Relación del estado del gobierno del Perú que hace el Marqués de Moncera [sic] al Virrey Conde de Salvatierra, 8 de octubre de 1648" (Hanke (t. 3) 1978: 186).

8 “Relación de la Audiencia de Lima a su sucesor el Conde de Castellar, 1 de agosto de 1674” (Hanke (t. 5) 1978: 26).

9 “Relación del Conde de Castellar a su sucesor, Don Melchor de Liñán y Cisneros, 13 de septiembre de 1681" (Hanke (t. 5) 1978: 118).

10 "Relación que hizo de su gobierno Don Melchor de Liñán y Cisneros a su sucesor, el Duque de la Palata, 8 de diciembre de 1681" (Hanke (t. 5) 1978: 233). 
Pero la monarquía ibérica, un gigante que se erguía sobre pies de barro, jamás tuvo la disposición de entregar parte de su preciado tesoro ultramarino a sus adversarios europeos: las posesiones americanas eran un importante pilar sobre el que sostenía su fuerza económica, y con la cual premiaba la lealtad de su nobleza mediante una política de otorgamiento de cargos que no hacía más que incrementar una ya numerosa burocracia. Tal ambiente de inseguridad contribuyó al moldeamiento de una animosidad colectiva dispuesta a abrazar las alternativas más drásticas que permitieran garantizar la seguridad deseada. Es así que en 1590 don García Hurtado de Mendoza, virrey del Perú, informaba al rey Felipe II que:

"enfrente del estado y provincia de Arauco, hay ciertas islas, que la una se llama de Santa María y la otra de la Mocha, y otras semejantes; estas islas tienen cantidad de indios y de comida y muy buenos puertos, y estos indios nunca quieren estar de paz [...] Todas las veces que han entrado corsarios en la Mar del Sur han tomado [en ellas] el primer puerto y noticia de lo que hay en la tierra, y proveídose de comida y agua en ellas [...]. Se podría mandar que los indios de estas islas de la Mocha y Santa María y las demás se fuesen sacando de ellas y llevándolos á este término de la Serena [...] despobladas estas islas no hallarían los corsarios el refresco y favor que allá [hallan] en los naturales de ellas cuando entran en la Mar del Sur, porque quitándoles la gente, cesaría el haber comidas y bastimentos en ellas"11.

\section{Primera Estrategia de Legitimación: la traición consumada}

A fines de marzo de 1684 un buque inglés al mando del capitán Swan, que había salido del puerto de Londres con encubiertas intenciones de piratería bajo una patente mercante (Barros Arana 2000: 170, Encina 1983: 172), intentó arribar al puerto de Valdivia, pero sus pretensiones fueron frustradas por la agudeza del gobernador de la fortaleza, quien ordenó abrir fuego contra la embarcación obligándola a retirarse al norte. Con la pérdida de algunos hombres y la merma de un número mayor de heridos, los expedicionarios atracaron en las costas de la isla Mocha para aprovisionarse de víveres y obtener alguna información útil para su derrotero posterior. Los naturales de la ínsula estaban lejos de sospechar las graves consecuencias que este simple desembarco habría de tener en sus vidas. Si bien es cierto que estaban al tanto del interés español por erradicar de sus posesiones cualquier presencia foránea que amenazara su hegemonía, no es menos cierto que en décadas pasadas el arribo de naves en cuyos mástiles flameaban las banderas de naciones enemigas de la metrópoli no se había traducido en un problema con las autoridades españolas. Pero el escenario había cambiado, y un fondeo de apenas 48 horas de la nave inglesa bastó para sellar sus destinos.

Como respuesta a la carta enviada por el virrey al presidente de Chile, el maestre de campo Gerónimo de Quiroga remitió dos caciques de la isla Mocha para que diesen razón de lo sucedido en base a una serie de preguntas que a continuación detallamos:

1. Que diesen cuenta de si fueron testigos del arribo del navío inglés, y de lo que sucedió entre la tripulación y los indios.

2. Que diesen cuenta de si dieron bastimentos a la gente del navío, en qué cantidad y especies.

3. Que informasen si los ingleses saltaron en tierra.

11 "Parecer dado por don García Hurtado de Mendoza al Rey acerca de despoblar ciertas islas en Chile, s/f (1590)" (Medina, 1901: 351-353). El documento también está reproducido en el tomo 4 de la segunda serie (Medina, 1960: 2-3). Las palabras del virrey, además de fundarse en antecedentes históricos como fue el desembarco que Francis Drake protagonizó en isla Mocha en 1578, fueron igualmente premonitorias respecto a acontecimientos futuros, como ocurrió con Richard Hawkins dieciséis años después. Un documento de la época dice que "habiendo tomado puerto el susodicho inglés en la isla de la Mocha, habitada de los dichos rebeldes, en 38 grados de altura este oeste dos leguas desviada de la ciudad Imperial, le dieron leña, agua, carneros y gallinas y otros bastimentos y comidas y siendo aquellas provincias inexpugnables de naturaleza, que no se han podido ganar de una gente aunque fiera [¿fuera?] desnuda en 46 años de continua guerra y porfía, bien se deja considerar la dificultad que había después que se juntasen con otra nación de más ingenio y policía, proveída y reparada de todos géneros de armas artificiosas"; véase el "Memorial de Domingo de Erazo a S.M. sobre el estado del reino de Chile, conforme a la instrucción y orden dada por el gobernador Martín García de Loyola, s/f (¿1597?)” (Medina, 1961: 3). 
4. Que informasen si en los días previos o posteriores avistaron otras embarcaciones de velas blancas o negras.

5. Es interesante constatar que el cuestionario a que fueron sometidos ambos lonkos se centraba en la indagación de dos puntos esenciales: en primer término (preguntas 1, 2 y 3), saber cuál fue la naturaleza de la relación entre lugareños y foráneos (pacífica o violenta), y si fuese el primer caso, si esta significó una ayuda material para los recién venidos; en segundo lugar, saber si las correrías de las naves enemigas eran frecuentes en torno a la isla (pregunta 4). Ambos espacios de saber apuntan a conformar una verdad potencial cuya intencionalidad está definida de antemano: que tanto los habitantes de la isla como la posición estratégica de la misma representaban una amenaza para la seguridad del reino.

Siendo interrogado el cacique Quilapichún, de Tirúa, por el maestre Pedro de Amasa, contestó que después de atravesar el mar en balsas para conchavar ovejas con los isleños, se encontró con el bajel inglés que provenía de Valdivia. La nave había dado fondo a puestas de sol, y no fue sino hasta el mediodía siguiente que se acercó una lancha con seis hombres "que conocieron eran moros, que así llaman a las naciones del norte"12. Precedidos de una bandera blanca, los europeos intentaron comunicarse a la distancia con los lugareños, y en medio de un lenguaje de gestos y palabras prácticamente incomprensibles para ambos, todo esto mediatizado por la desconfianza, un mocetón se acercó a los recién llegados, recibiendo cuatro cuchillos y seis mazos de chaquiras para que los repartiese entre los suyos. Frente a este indicio de aparente confianza y buena voluntad, tanto Quilapichún como el cacique Aguigüenu, natural de la isla, se dirigieron a caballo hacia la lancha en que los ingleses les esperaban, y estos en una acción repentina los hicieron subir al bajel a la fuerza. Obligados a pernoctar bajo cubierta, Quilapichún indicó a su interrogador que a la mañana siguiente supo por señas de sus captores que "en Baldiuia hauian muerto seis de dichos inglesses y que uno de ellos que le pareció era el capitan estaua erido en el brazo ysquierdo" 13 . Al final, ambos fueron dejados en libertad, recibiendo como compensación un sombrero y una espada. Pedro de Amasa inquirió sobre la ayuda económica que se habría brindado a los corsarios, a lo cual Quilapichún contestó que:

"el casique Ramipillán les dio cinco ouejas, otro yndio llamado Lepuante una oueja, otro yndio Guaiquibilo otra, otro yndio de Quelentaro que no saue su nombre otra, y así mismo Ranguepichan otra, y otras quatro les dieron dichos yndios que no se acuerda de sus nombres, y que otros tres yndios llamados Melipillán, Pichaleco y del nombre del otro no se acuerda, les dieron una cesta de papas cada vno, y que en re. torno les dieron cuchillos y chaquiras"14.

Apuntó que el navío levó anclas y se marchó después de dos días. En torno a la última pregunta, dijo no saber de otros navíos rondando la isla, aparte del referido en su testimonio.

Llegado el turno de Aguigüenu, el lonko ratificó lo señalado por su compañero, agregando que una vez liberados en tierra, unos caciques de la isla:

"llamados Caiunpangue, Quechanaguel, Eniptureo, Millatipay, Elentaro, Tamepilla, Guenubilo [y] Melicheuque, lleuaron a dichos yngleses carneros y ouejas, gallinas, papas y maiz, que por todas serian veinte ouejas y carneros y que aunque auian traido muchas a la plaia por que todos fueron a conchauar como la lancha se fue al navio no lleuaron mas por que, y por paga de dichos bastimentos les dieron cuchillos y chaquiras" ${ }^{15}$.

12 “Información de la llegada del navío inglés a la isla de la Mocha; Santiago, 30 de mayo de 1684: declaración del cacique de Tirúa, Quilapichún", B.N.O.M., t. 323, f. 420. El término "moros", muy común en la documentación de la época, era utilizado para señalar a los miembros de naciones infieles, o más exactamente, a quienes no participaban del rito y creencias propias del catolicismo.

13 Ibídem, f. 421.

14 Ibídem.

15 “Información de la llegada del navío inglés a la isla de la Mocha; Santiago, 30 de mayo de 1684: declaración del cacique de la Mocha, Aguigüenu”, B.N.O.M., t. 323, f. 424. 
Es importante señalar que ninguna de las pesquisas posteriores arrojó una información como la que hemos destacado, por lo que consideramos válido suponer que el testimonio de Aguigüenu pretendía establecer un principio de inocencia y una posición de lealtad de los isleños para con la monarquía hispana, más allá de la sinceridad de sus palabras. En el fondo, la supuesta traición que representaría la entrega de carneros, ovejas, gallinas, papas y maíz, fue morigerada por la fallida pretensión de captura de los enemigos de España.

Por auto del 31 de mayo de 1684, el gobernador ordenó que las declaraciones de los caciques se remitieran al maestre de campo Gerónimo de Quiroga para que continuase indagando a otros caciques e indios. Solicitando la asistencia del Protector General de Indios, capitán Francisco Ximenes de Herrera, y la del teniente Xil de Sosa en calidad de intérprete, el 1 de julio de 1684 se dio inicio a una serie de interrogatorios. El primero en comparecer fue el indio Marilicán, natural de la isla, quien no difirió en lo más mínimo de lo señalado por Quilapichún y Aguigüenu, con la única salvedad de precisar que los indios que entraron en el bajel fueron tres, ya que el lonko de la isla se hizo acompañar de un paje llamado Guinimante $^{16}$. En el mismo día declaró el cacique Licanpangui, también isleño, quien se apegó sin mayores divergencias a la versión recién indicada, excepto en la indicación de que hacía dos meses había visto un navío de velas blancas con dirección a Concepción.

Al día siguiente, 2 de julio, testificaron los caciques Negueyante y Gueyquivilo, junto al indio Ibuncheu, todos de Tirúa, además del indio Marinaguel, oriundo de Ranguilgue ${ }^{17}$, y nuevamente expusieron una declaración similar, coincidiendo todos con Licanpangui -a excepción de Ibuncheu- en el avistamiento del navío de velas blancas con ruta a Concepción dos lunas atrás, el cual al parecer "era vno que venia de Chiloe"18. Sin embargo, en el interrogatorio de Gueyquivilo aparece un dato de sumo interés: el lonko niega haber visto algún navío de velas negras antes o después del navío inglés, "porque el cazique Aguigüenu auia dicho que vido dos navíos de velas negras". A más de señalar que el interrogado negó haber divisado o sabido del paso de dichas naves, lo interesante del asunto es que en su declaración del 30 de mayo el lonko aludido, Aguigüenu, no hizo una mención explícita del avistamiento de algún navío de velas negras, aunque sí se hace referencia en el interrogatorio a "los nauios que [antecedentemente] hauissaron al Señor Presidente estando en la ciudad de la Conzepzion"19. La ambigüedad del dato no nos permite dilucidar el problema de si la mención a las embarcaciones de velas oscuras era parte del inicio del proceso, o si dicha apreciación aparece cuando este ya había dado pie: una reflexión como esta parecerá bizantina, carente de verdadero sentido y trascendencia, pero como veremos no deja de tener asidero. El día 3 de julio fue el turno del cacique Guaiquiñanca y del indio Tanamacho, ambos de Tirúa, cuyas versiones no difieren en lo esencial de la mayoría de los declarantes. Finalmente, al día siguiente el testimonio de Alcamanque, cacique de Tirúa, permaneció fiel a la versión de la mayoría.

La contradicción que se estableció entre las palabras de Aguigüenu con la declaración del resto de los testigos en lo que respecta a la aparición de unos navíos de velas negras, obligó a Gerónimo de Quiroga a levantar un auto el mismo 4 de julio de 1684, con el fin de establecer un careo entre el cacique y sus pares que permitiera dilucidar el desacuerdo. Llegada su oportunidad, Aguigüenu insistió en su versión inicial sobre la presencia de "dos nauios y que vreue se desaparecieron... [y él] los vido solo y que vien los pudieron ver otros yndios de la ysla de la Mocha porque pazaron de dia y breue se desaparecieron" ${ }^{20}$, a lo que

16 “Información de la llegada del navío inglés a la isla de la Mocha; Concepción, 1 de julio de 1684: declaración del indio Marilicán de la Mocha”, B.N.O.M., t. 323, f. 428.

17 Rewe costino de la wichanregua de Purén.

18 “Información de la llegada del navío inglés a la isla de la Mocha; Concepción, 2 de julio de 1684: declaración del cacique Negueyante de Tirúa”, B.N.O.M., t. 323, f. 438. En el fondo, se indica la probable adscripción española de dicha nave, por lo que no representaría una amenaza.

19 "Información de la llegada del navío inglés a la isla de la Mocha; Santiago, 30 de mayo de 1684: declaración del cacique de la Mocha, Aguigüenu”, B.N.O.M., t. 323, f. 424.

20 “Careamiento del cacique Aguigüenu y los demás testigos; Concepción, 5 de julio de 1684”, B.N.0.M., t. 323 , f. 464. 
sus detractores contestaron inquisitorialmente preguntándole:

"cómo, dónde o quando vido los dichos nauios porque ninguno de todos los yndios de la ysla de la Mocha no auían visto tales navíos ni entre ellos en la dicha ysla tal cosa no se auia ablado oydo ni entendido pues todos auian estado en la ysla de la Mocha y tratado de esas materias del nauio del yngles y que ellos ni ningun yndio de la ysla de la Mocha digeron aver visto tales nauios y que asi lo an dicho en sus declaraciones que todos unánimes y conformes comuinieron en las declaraciones que tienen echas y se ratificaron en que no auían visto ni sauido de tales nauios y que se afirmauan y rratificauan en ello"21.

A pesar de una nueva insistencia de Aguigüenu, los indios mantuvieron su postura inicial. Este escenario de versiones contradictorias se complejizó aún más con la intromisión de un nuevo actor: Gerónimo de Quiroga volvió a expedir un auto el 15 de julio, por el cual ordenó que nuevamente fuesen reunidos los indios declarantes, ya que por causa de la información brindada por una india cristiana, sospechaba que hubiesen mentido, y que en consecuencia los ingleses sí habían bajado a tierra, reconociéndola y tomado bastimentos; según el documento, el maestre de campo señalaba que:

"Es venido a mi noticia por la que dio vna yndia cristiana nombrada Lorenza del seruicio del capitan Fernando Carlier que los dichos caciques e yndios no auian declarado en las declaraciones que auian echo [dicho] la verdad de lo que abia pasado con los yngleses en la dicha ysla, lo qual se lo dijo vn tio suyo nombrado Gua[y]quivilo natural de Tirua y el tambien y que auian mentido por que los yngleses auian saltado en tierra en la dicha ysla de la Mocha y paseadola a pie y a caballo y dormido en ella y lleuado bastimentos"22.

El testimonio de una india -caso ex- traño, dada la menor estima que en el mundo español se daba a voz de las mujeres, y más aún si era indígena- ponía en entredicho a los declarantes y reafirmaba la posición de Aguigüenu, situación más que complicada si se considera que las palabras de la mujer se sostenían, aparentemente, en la confidencia de un indio de Tirúa. Tanto la veracidad como la credibilidad de los testimonios eran puestas en tela de juicio, y con el sustento de la nueva propuesta se abrían las puertas a la acusación de traición y deslealtad para con la Corona. De este modo, el mismo día procedió a declarar la india Lorenza, quien a diferencia de los demás era cristiana, por lo que podía tomársele juramento, lo que en la concepción de la época otorgaba mayor peso y aceptación jurídica a sus palabras ${ }^{23}$; en el testimonio señaló que:

"lo que saue y pasó es que vna noche estando en la cosina de su caza donde iba a senar vn yndio nombrado Guayquibilu, tio de esta declarante, le dijo el dicho indio Guaiquivilu [sic] que todos los yndios mentian en quanto abian declarado y el tambien porque asi lo auian tratado todos los caciques e yndios para que no lo supiesen los españoles. Y que la verdad era que los yngleses llegaron a la ysla de la Mocha y echaron otro dia la lancha con vandera blanca y los yndios se fueron a la lancha de su voluntad con camaricos de ganados y los yngleses saltaron en tierra y subieron a caballo y corrieron toda la ysla y se quedaron a dormir en los ranchos de los caciques y les dieron muchos agasajos de chaquiras de vidrios, cuchillos, espadas y vaieta blanca [...] y que esto es lo que saue porque se lo dijo el dicho yndio Guaiquivilu su tio y que ella se lo dijo a su señora luego, y que su señora lo oyo y se lo dijo a unos casiquillos de la Mocha"24.

Frente a esta información, se hizo declarar nuevamente a Aguigüenu, quien el mismo 15 de julio rectificó parte de su declaración inicial, reconociendo ahora que "era verdad que los yngleses saltaron en tierra en

21 Ibídem, fs. 464-465.

22 "Auto de 15 de julio de 1684: sobre falso testimonio de los indios", B.N.O.M., t. 323, f. 468.

23 Una compensación, igualmente jurídica, a su condición de mujer.

24 “Auto de 15 de julio de 1684: declaración de la india Lorenza”, B.N.O.M., t. 323, f. 470. 
la dicha ysla de la Mocha y que no lo auia dicho porque los caciques le digeron en la ysla que lo negase, que ellos lo vendrian a decir"25. Agregó además que algunos de los ingleses que bajaron a tierra dispararon sus armas y se llevaron algunas ovejas, se aprovecharon de las chinas y durmieron dos de ellos en el rancho del cacique. Un capitán del bajel les preguntó si sabrían guiarlos por tierra hasta Valdivia desde Tirúa, a lo que contestaron que no, percatándose que el capitán estaba herido a raíz de una escaramuza que habían sostenido en ese puerto con las fuerzas españolas, justificando ante la autoridad que toda esta información la había callado "porque los caciques de la Mocha Quitalab y otros digeron que no lo declarase porque no se enojase el Señor Gobernador porque no auian cogido a los moros como se lo auia mandado Su Señoria"26.

Como un cuento de nunca acabar, la declaración del lonko instó al maestre de campo a ordenar la presencia de los caciques e indios que habían testificado antes, previniendo que fuesen puestos "distintos y separados donde no se comuniquen"27. Empero, y a pesar de haberlos separado e incomunicado para que no se pusieran de acuerdo en sus aseveraciones, el cacique Quilapichún, el cacique Marilicán, el cacique Licanpangui, el cacique Negueiante, el indio Ibuncheo, el indio Marinaguel, el cacique Guaiquiñanco, el indio Tanamacho y el cacique Alcamanque se reafirmaron en su primera declaración, aseverando todos que tanto la india Lorenza como Aguigüenu mentían, este último muy probablemente porque "le habían de dar vino por que digese eso que a declarado, que es vn grande embustero" 28 . Lo que es más, el cacique Quilapichún sugirió que "para que mejor fuese creido que enviasen a la ysla de la Mocha vn español que se ynformasen de todo y que si allasen que este declarante auia ocultado la verdad y no la auia declarado que le cortasen la caueza a el y a sus compañeros, por que ni los moros saltaron en tierra ni subieron en caballos ni corrieron ni dispararon, y que esta es la verdad y que no a pasado otra coza ni saue mas de lo que tiene declarado" 29 . Similares detalles entregó en su declaración el cacique Guaiquiñanco, de Tirúa ${ }^{30}$.

La uniformidad de testimonio de los indios acusados, así como la decidida posición de algunos de ellos, invita a pensar en un fundamento de verdad en sus declaraciones. Más aún, el hecho de que el cacique Guaiquivilu, el supuesto informante de su sobrina Lorenza, se encontrase enfermo en el preciso instante en que se le conminó a declarar, va consolidando la idea de una maquinación fraguada en el seno del mundo español para establecer un principio jurídico (la seguridad del reino amenazada por los corsarios y la eventual traición de los indios) que legitimase una decisión tan drástica, como sería el despueble total de la Isla Mocha. En fin, la piezas dispersas del comienzo del proceso parecen encajar en su fracción final cuando el cacique Aguigüenu, al ser nuevamente encarado con sus detractores, reconoció "que aquellos caciques desian verdad y que el auia mentido en la declaración que auia echo y que aquello auia declarado de miedo, por lo que la yndia Lorenza auia dicho temeroso de que lo asotasen o castigasen y que no auia otra coza mas de lo que auia declarado en la ciudad de Santiago ante el corregidor Don Pedro de Amasa"31. No hubo barcos de velas negras, ni los corsarios pusieron pie en la isla: el contacto entre indígenas e ingleses había sido algo menor, limitado al intercambio de unos pocos bastimentos por adornos de escaso valor y el obsequio de algu-

25 “Auto de 15 de julio de 1684: declaración del cacique Aguigüenu de la Isla Mocha”, B.N.O.M., t. 323, f. 472.

26 Ibídem, f. 474. La referencia al mandato del gobernador de capturar a los enemigos del rey se asienta en los tratados suscritos entre españoles y reche-mapuches en las paces de 1641, 1647 y 1666.

27 "Auto del 16 de julio de 1684, sobre que los caciques e indios ratifiquen o refuten sus declaraciones iniciales", B.N.O.M., t. 323 , f. 475

28 "Auto del 16 de julio de 1684, sobre que los caciques e indios ratifiquen o refuten sus declaraciones iniciales: declaración del indio Ibuncheo de Tirúa”, B.N.O.M., t. 323, f. 484.

29 "Auto del 16 de julio de 1684, sobre que los caciques e indios ratifiquen o refuten sus declaraciones iniciales: declaración del cacique Quilapichún de Tirúa”, B.N.O.M., t. 323, f. 477.

30 "Auto del 16 de julio de 1684, sobre que los caciques e indios ratifiquen o refuten sus declaraciones iniciales: declaración del cacique Guaiquiñanco de Tirúa”, B.N.O.M., t. 323, f. 486.

31 "Careamiento de los indios testigos y del cacique de la Mocha Aguigüenu; Concepción, 18 de julio de 1684", B.N.O.M., t. 323, f. 493. 
nos cuchillos de parte de los europeos. Nada que pudiera justificar, jurídica y moralmente, un desarraigo.

Pero la pretensión de algunas autoridades españolas encontró un camino alternativo: la conciliación entre la seguridad del reino y el traslado de los mochanos se explotó al nivel de los estereotipos.

\section{Segunda Estrategia de Legitimación: el despliegue de los estereotipos}

Introducirnos en el tema de los estereotipos implica adentrarse en una dimensión de las prácticas discursivas: la de los imaginarios respecto a la alteridad. Partimos del supuesto de que todo discurso es un objeto históricamente producido e interpretado, esto es, que se halla situado en el tiempo y en el espacio. Siguiendo a Theo van Leeuwen (citado en Wodak 2003: 28), observamos que el discurso es al mismo tiempo un instrumento de poder y de control, y también un instrumento de la construcción social de la realidad. El lenguaje, al conferir una estructura a la experiencia, es la unidad básica de todo discurso, incluso de aquellos de naturaleza no verbal (por ejemplo, el uso de las imágenes), y en tal sentido se halla íntimamente entrelazado con el poder social de un buen número de maneras: el lenguaje clasifica el poder, expresa poder, está involucrado allí donde existe un desafío al poder o una contienda para conseguirlo (ibídem: 31). De acuerdo a Sigfrid Jäeger (2003: 63), "el discurso es el fluir del conocimiento a lo largo de toda la historia, fluir que determina los hechos individuales o colectivos, así como la acción formativa que moldea la sociedad y que, de este modo, ejerce el poder". En suma, en su ligazón con el poder, los discursos se encuentran vinculados a la acción.

Ahora bien, si reconocemos que el discurso es una unidad creadora de conciencia, y que al operar en un contexto dado crea las condiciones para la formación de sujetos y la estructuración y configuración de las sociedades, entonces nos daremos cuenta de que los discursos también pueden ser considerados como un medio de producción social. En tanto que "agentes de conocimiento (válido en un determinado lugar y en un determinado momento), los discursos ejercen el poder [...] son un factor de poder, ya que son capaces de inducir comportamientos y de generar (otros) discursos. De este modo, contribuyen a la estructuración de las relaciones de poder en una sociedad" (ibídem: 68). Siguiendo al mismo autor, adherimos a la hipótesis de que "los discursos ejercen el poder porque transportan un saber con el que se nutre la conciencia colectiva e individual, así como el fundamento de la acción formativa que moldea la realidad" (Ibídem: 69).

Los estereotipos, en tanto imágenes o ideas aceptadas comúnmente por un grupo o sociedad, actúan como dispositivos de poder, es decir, como formaciones cuya principal función en un punto histórico dado consiste en responder a una urgencia: el dispositivo, por tanto, tiene una función principalmente estratégica (Foucault 1983: 78). Desde esta perspectiva, el estereotipo viene a ser una construcción simplificada de una identidad alterna. El manejo de imágenes respecto al indio, es decir, la manipulación estratégica del campo semántico que envolvía a este concepto, fue una práctica que se identificó con el comienzo del contacto hispanoindígena en el Nuevo Mundo. Para el caso chileno, ya en los inicios de la Conquista el capitán extremeño Pedro de Valdivia hablaba de "los indios naturales cuam [sic] mentirosos son e huidores, no por el mal tratamiento que [...] se les hace, ni trabajos excesivos que se les dan en el sacar del oro, ni por falta de mantenimientos que tengan, sino por ser bellacos y en todo mal inclinados" ${ }^{32}$. El estereotipo del indio como un ser traidor y vil está implícito en el fragmento.

Para el caso de la isla Mocha, contamos con escasas referencias previas a su traslado al continente. En el siglo XVI, Juan López de Velasco (1571-1574), en su Geografía y Descripción de las Indias, caracterizó a la Mocha como "frontero de la Imperial, de seis leguas de boxo y tres de largo, poblada de mil indios todos de guerra". A comienzos del siglo XVII, Fray Diego de Ocaña (1607: 37) coincidió en esta apreciación al señalar que "tiene muchos indios que de continuo han estado de guerra". Consideramos que la condición de

32 Cabildo de Santiago, sesión del 7 de enero de 1550 (Arteaga, 1861: 227). 
indios rebeldes que se les atribuye, obedece más al hecho de que la isla se encuentra a la misma latitud en que se repartían en el continente las parcialidades más reacias a la intromisión española (Tucapel y Purén, y algo más alejada Arauco), antes que a un conocimiento acabado y bien informado. Si bien es cierto los nativos de la Mocha formaban parte de la wichanregua de Purén (Goicovich 2006: 563), es prácticamente nula la evidencia que hable de una permanente movilidad de contingentes en armas desde este sistema insular hacia el continente.

Pero con el problema de la amenaza de ultramar, los habitantes de la isla se convirtieron en depositarios de una serie de epítetos semantizadores que recuerdan, en cierta medida, todo ese complejo debate que se gestó en la metrópoli a comienzos de la expansión en América. Gran artífice de esto fue el gobernante José de Garro, quien no cejó en su afán de implementar medidas de defensa contra las agresiones de los filibusteros. Queriendo privar a estos de los recursos que pudieran hallar en aquellos puntos de la costa que no era posible defender militarmente, dispuso que se retiraran los ganados más al interior; y mandó colocar vigías en las alturas más cómodas para este objetivo, a fin de que dieran oportunamente aviso para que se pusieran a salvo los pobladores de los puntos amenazados (Barros Arana 2000: 173). En su plan para asegurar al reino de cualquier posible invasión o escaramuza con los enemigos de Europa, la isla Mocha representaba un escollo al que había que dar pronta solución. De esta manera, con el fin de atender a la carta del virrey Duque de la Palata, de 7 de marzo de 1684, José de Garro solicitó sus opiniones a diversas autoridades civiles y militares para aprobar el despoblamiento de la isla y el traslado masivo de los indios al continente. Aunque no es un legajo numeroso en páginas, no por ello deja de ser de interés escrutar en los planteamientos de los consultados.
Interesa destacar que ya el 2 de julio de 1684, José de Garro había propuesto, mediante un Decreto, el traslado de los indios al continente, ya que "con esto se facilitaría su evangelización y la vida en policía, cuyos frutos ya se observaban en otros indios del continente" 33 . Además, el mismo Decreto establecía que tanto los Oidores de la Real Audiencia, así como el Obispo de Santiago, Fray Bernardo Carrasco, y los Padres Provinciales de las diversas órdenes, debían pronunciarse en torno al tema del traslado de los naturales al continente ${ }^{34}$. No deja de llamar la atención que en esa fecha recién se iniciaba la segunda ronda de interrogatorios a los indios acusados de ocultar información sobre el navío inglés, lo que da cuenta de que el gobernante manejó dos posibles vías de legitimación en forma paralela: la suerte de los mochanos estuvo fijada con bastante antelación.

En el Decreto, José de Garro hizo ver que al estar los indios bajo la obediencia de Su Majestad, habían cometido grave delito contra su real servicio por haber abastecido a los piratas ${ }^{35}$. Sin manejar el típico estereotipo del "indio traidor", el gobernador centró su inquietud en la inconsistencia y flaqueza de espíritu de estos naturales, y que por lo mismo se habrían de esperar mayores inconvenientes en el futuro al aprovecharse los enemigos de los bienes que allí se producían, sin descartar el temor de que los piratas "podrían poblar la isla de Juan Fernández con estos naturales, para que siempre que recalen allí dispusieran de bastimentos" 36 . En fin, José de Garro destacó las ventajas temporales (reducción de estos indios a pueblos y consecuente vida en policía) y espirituales (conversión) que traería la transportación, además de recalcar que el delito cometido (abastecer al enemigo del rey) podía justificar por sí solo su traslado ${ }^{37}$.

El 5 de agosto dio su parecer Fray Bernardo Carrasco, obispo de Santiago, quien refirió dos puntos para justificar la transportación. En primer término, citando a autores clásicos

\footnotetext{
33 "Decreto del Presidente por el que dispone que el Obispo de Santiago y Provinciales de las Ordenes den su parecer acerca de lo indicado por el Virrey; Santiago, 2 de julio de 1684", B.N.O.M., t. 323, fs. 413-414.

34 Ibídem, f. 415.

35 Ibídem, f. 414.

36 Ibídem.

37 Ibídem, fs. 414-415.
} 
como San Agustín, resaltó el hecho que la vida en retiro, como es el caso de una isla apartada y con escasa integración entre sus mismos habitantes, es propia de los animales, "ya que la vida en ciudades permite que surja el derecho de gentes" ${ }^{38}$. En la concepción de los siglos XVI y XVII, estos seres al margen de la civilidad eran "hombres naturales", criaturas que habían escogido vivir fuera de la comunidad humana: "tales criaturas asociales eran menos que humanos, porque se habían apartado de los medios que Dios había otorgado a cada hombre para que pudiera lograr su fin" (Pagden 1988: 27-28). Vivir fuera del esquema de un sistema urbano, o al menos próximo a él, significaba no detentar los beneficios de los aditamentos organizativos que permiten que un sistema tal funcione: la disciplina amparada por la ley, el orden que garantiza el apego a las normas, la justicia y el bienestar público debidos al celo del gobernante y sus ministros. El caos de la vida salvaje impide que surja esa tendencia a la vida social que anida en los corazones de todos los hijos de Dios, y ello es un obstáculo para su evangelización (el orden espiritual debe estar respaldado por un orden social) y su felicidad. De esta manera, frente a la amenaza de la "natural fiereza" ${ }^{39}$ que suele aflorar en el alma de quienes llevan esta forma de vida, el obispo enfatizó que "quien gobierna puede, por penas y multas, hacer que los que habitan en los desiertos vengan a ser habitadores de la ciudad" ${ }^{40}$, o en este caso, de quienes habitan en islas. Por lo demás, indicó que evangelizar en la isla presentaba la dificultad de mantener operarios en ella, y de ser el número de los naturales muy reducido. El traslado, en definitiva, beneficiaría principalmente a los niños, cuyas almas gozarían tempranamente del credo, al mismo tiempo que los herejes de Europa estarían imposibilitados de abastecerse al carecer de los brazos que hagan producir la tierra ${ }^{41}$.
El segundo punto considerado por el obispo fue el eventual rechazo de los indios a trasladarse, quienes podrían confederarse con los de tierra firme una vez puestos en el continente. En su opinión, el mejor modo de prevenir esto sería otorgándoles a los desarraigados las mejores tierras posibles, de modo tal que la abundancia y prosperidad del nuevo espacio les hiciera olvidar su anterior pobreza. Dejarlos en la isla sería permitirles vivir como bárbaros e irracionales, por lo que también había que destruir las pertenencias que los ligaban a la idolatría ${ }^{42}$. El término "bárbaro" detentaba en esta época una doble connotación: para referirse a semihombres (u hombres incompletos) por la carencia de la razón, vale decir, de la facultad de tomar las decisiones más correctas en procura del fin supremo de la felicidad, y a la vez para dar cuenta de seres paganos, personas alejadas de la verdad suprema que es la que orienta y educa la esencia del hombre que es su alma (Pagden 1988: 41). Por esto, no es casualidad que el obispo se refiera a los mochanos con términos como "lo detestable de sus inclinaciones", "vivir como irracionales", "sus antiguos ritos y dogmas ydolatrando", o "antiguas e yncultas costumbres". En suma, el obispo ponderó las ventajas que se derivarían del traslado en "euitarse con esta diligencia las continuas ofensas a Dios nuestro Señor, que en la dicha ysla haçen los yndios, y juntamente el euitarse vna espia del enemigo pirata y azilo con que se pueda mantener" 43 .

Seguidamente, Fray Tomás Moreno, Provincial de los franciscanos, en su informe de 26 de septiembre, coincidió con el obispo en que sería lícito transportar a los indios a tierra firme, "dándoles tierras suficientes para su labranza y crianza, con que se puedan sustentar más cómodamente que en la isla" ${ }^{44}$. Apoya su argumentación en los postulados del doctor Juan Duns Escoto, teólogo escolástico y filósofo

38 "Los motivos que dan mérito a justificar la trasplantación que se intenta hacer de los indios de la isla de la Mocha a los términos de esta ciudad se verifican por las razones siguientes. Fray Bernardo, obispo de Santiago de Chile; 5 de agosto de 1684", B.N.O.M., t. 323, f. 498.

39 Ibídem, f. 499.

40 Ibídem.

41 Ibídem, fs. 499-500.

42 Ibídem, f. 501.

43 Ibidem, f. 502.

44 "Informe sobre la misma materia de Fray Tomás Moreno, provincial de los Franciscanos; Santiago, 26 de septiembre de 1684", B.N.O.M., t. 323, f. 504. 
medieval escocés para quien "el príncipe cristiano lícitamente puede bautizar a los hijos de los infieles sus vasallos, aunque éstos lo repugnen, y por el peligro de subversión, quitárselos y transportarlos a donde tengan la instrucción y educación" ${ }^{45}$. En el fondo, el provincial de los franciscanos manipuló los estereotipos de la "gentilidad" y la "fiereza" de los indios, pero a la vez, y ligado a esto último, la de su "barbarismo", ya que los naturales estaban incapacitados de tomar las decisiones adecuadas no solo para sí mismos, sino para con sus propios hijos al condenarlos a permanecer en la miserable e idolátrica vida que ellos han llevado. Resulta de sumo interés observar que la reflexión de este religioso estuviese centrada, en último término, en el bienestar de los infantes, posición que le permitió elevarse sobre el estrado de la "ética" para enjuiciar la conducta de las generaciones adultas.

Pero, paralelamente, el sacerdote franciscano se sitúa también en un nivel jurídicopolítico ya que, argumenta, siendo los mochanos vasallos del rey, y a pesar del derecho de gentes a vivir en sus tierras, "por el bien y utilidad de sus almas podrán ser transportados en nombre del rey, para que reducidos a estado político, estén más hábiles para recibir la fe" ${ }^{46}$. Como en el caso anterior, nuevamente se están ponderando las virtudes del homo civitatis, el ser que al someterse a las normas de la vida social y política, es capaz de controlar sus instintos naturales, moderar y hasta domesticar sus pasiones, y en la calma de los espacios normados hallar siempre la mejor alternativa para alcanzar sus fines.

Apenas diez días más tarde, el también franciscano Fray Alonso Briceño, informó su parecer a las autoridades, reduciendo la consulta del gobernador José de Garro a tres puntos:

a) Si era lícita la trasmigración de los naturales por el delito de comercio y confederación con el enemigo.

b) Si era lícita la trasmigración por las facilidades que implicaría para la evangelización. c) Si era lícita la trasmigración en razón de la defensa frente al enemigo pirata por parte de los españoles o por parte de los indios.

En torno al primer punto, la postura del franciscano es que el delito señalado no daría pie a la trasmigración, porque aunque los indios hubiesen realizado comercio ilícito con los enemigos de España proveyéndolos de víveres, se entiende que lo hicieron presionados por el miedo de una eventual represalia. Es importante destacar que Fray Alonso Briceño sustentó esta postura en el dato de que los naturales se vieron obligados a entregar sus propias mujeres al enemigo a fin de no ser agredidos, hecho que bien sabemos jamás ocurrió, según consta en la retractación del lonko Aguigüenu abordada en líneas previas. De esta manera, es fácil conjeturar que cuando menos algunos de los informantes sustentaron sus argumentos sobre la base del conocimiento de hechos fragmentarios e incluso irreales.

En lo que respecta al segundo punto, la postura del consultado es igualmente negativa como fundamento de legitimación del desarraigo, ya que en sus palabras "los predicadores evangelicos devemos especialmente seguir la doctrina y pasos de Jesucristo, nuestro Diuino Maestro, quien busco personalmente a los pecadores e infieles, y embio diversas veses a sus Apostoles a predicar su sagrada doctrina, como refieren en tantas partes los quatro Evangelistas. Y assí Apostol quiere decir embiado, legado, embaxador" ${ }^{47}$. Por esto, los naturales no pueden ser erradicados de su tierra en función de la predicación evangélica, antes bien, deben ser buscados y doctrinados al interior de ella. Es más, si por causa de la predicación se hiciera lícito desarraigar a las gentes de su terruño, entonces la religión cristiana se haría odiosa. Argumenta, finalmente, que si bien en el Segundo Concilio Limense se ordenó que la población espaciada por diversos ranchos se reduzca a pueblos, esta disposición no implica una trasmigración, aunque sea a una zona de igual clima que la originaria.

Pero es en el tercero y último de los

\footnotetext{
45 Ibídem.

46 Ibídem.

47 “Informe del franciscano Fray Alonso Briceño, 3 de octubre de 1684", B.N.O.M., t. 323, f. 525.
} 
puntos que el religioso muestra una postura decididamente opuesta a las anteriores, ya que según su concepto la defensa tanto de la soberanía española como de la integridad de los indios eran motivos válidos para trasladar a los naturales de sus tierras de origen. La seguridad del reino, que implicaba garantizar los intereses del rey y el bienestar de sus vasallos (en este caso, los naturales), era una condición que se imponía por sobre todas las ya señaladas, de modo tal que "por la una y otra defension no solo puede, sino es que deue en conciencia Su Señoría usando de la potestad dominatiua transmutar a los susodichos indios de su natural domisilio, habitación y Patria"48. Junto a esto, el religioso refuerza su argumentación en el riesgo que involucra la "veleidad natiua [por la cual los indios] estan expuestos a socorrer al enemigo corsario, y aun a sembrar cada dia mas con la codicia de los tratos y contratos con dichos enemigos" ${ }^{49}$ : nuevamente aflora la idea de la naturaleza inconstante de los indios, es decir, poco leal e inclinada irremediablemente a la traición.

Una postura similar había manifestado Fray Ramón de Córdoba solo un mes antes. Este capellán sopesó los motivos de la transportación de los mochanos, reduciéndolos básicamente a dos: las ventajas que significaría para la educación cristiana de los naturales, y la seguridad del reino. En primer lugar, el religioso consideró que el reparto del pasto espiritual entre los indios no podía justificar un desarraigo, ya que "assi nos lo enseño Cristo por nuestro bien, enviando a sus apostoles" 50 . Pero al igual que Fray Tomás Moreno, estaba convencido de que la seguridad del reino era una prioridad que se superponía a cualquier otra consideración, ya que antes que todo debía preponderar "la causa y bien público al particular [por lo cual] con la misma justificación que pudiera Vuestra Señoría, en nombre de Su Majestad despoblar cualquier ciudad, teniendo orden para ello, su era ofensiua y perniciosa a las otras partes de este Reyno podra aser lo mismo con toda justificación respecto de la ysla de la Mocha, aunque sus agitadores fuesen ynofensissimos y libres de toda culpa en el seruicio de el Rey" 51 . A esto el religioso suma la inconstante naturaleza de los indios, quienes están "vehementemente notados de infidelidad" 52 , apreciación similar a la de Moreno.

Los fundamentos de legitimación del traslado fueron ponderados en forma algo distinta por Fray Pedro de Oro Bustamante, vicario provincial de la Merced. En un extenso informe, el sacerdote consideró tres variables a considerar:

a) "Es muy conforme al derecho natural y de las gentes que los hombres viuan vida politica sociable" ${ }^{53}$.

b) Los indios deben ser evangelizados donde "con mas comodidad puedan ser industriados en la religión catholica" ${ }^{4}$.

c) Por razones de seguridad, se debía evitar que recibieran apoyo de cualquier tipo "los enemigos de la Corona de España y pyratas del mar" 55 .

Los tres fundamentos fueron considerados como favorables y suficientemente legitimantes por el religioso, para obligar a los naturales a abandonar la isla. En lo que se refiere al primer punto, Pedro de Oro destacó que la poca comunicación y comercio que imponía una vida insular hacía que los mochanos fueran de una condición similar a la de las fieras, vale decir, de escasa o nula virtud racional. De esta manera, "siendo esto tan contrario a la naturaleza sociable del hombre, no parece justo dexarlos en este estado" ${ }^{56}$. Ya a fines de

\footnotetext{
48 Ibídem, f. 528.

49 Ibídem, f. 529.

50 “Informe de Fray Ramón de Córdoba, 28 de agosto de 1684”, B.N.O.M., t. 323, f. 514.

51 Ibídem, f. 515.

52 Ibídem.

53 Informe de Fray Pedro de Oro Bustamante, vicario provincial de la Merced, 20 de septiembre de 1684", B.N.O.M., t. 323, f. 506 .

54 Ibídem, f. 508.

55 Ibídem, f. 511.

56 Ibídem, f. 506
} 
la centuria precedente el padre José de Acosta, en su clasificación de las formas de organización de las sociedades americanas, había situado a los habitantes del área centro-sur de Chile en un nivel inferior al de mexicas e incas, ya que vivían en poblados y no en ciudades, y no estaban gobernados por reyes sino que por consejos, excepto en los momentos de conflicto en que escogían a un líder cuya autoridad desaparecía tan pronto el peligro cesaba. En palabras del sacerdote jesuita (1590: 305), estos indios vivían "en comunidades y behetrías, donde hay alguna más orden y asiento, como son hoy día los de Arauco y Tucapel en Chile", con lo cual ubicaba a los reche-mapuches en un nivel intermedio entre las civilizaciones y el salvajismo. Es dentro de esta lógica que Pedro de Oro establece su argumentación, ya que la precaria condición social y política de los naturales los hacía seres incapaces de velar por su propio bienestar, actuando de esta manera bajo el manto de la más completa ignorancia. Nos dice el sacerdote en su informe que:

"muchos y graues Doctores en derecho son de parecer que puede el Principe y los que en su nombre gobiernan hacer colonias y transportar sus vasallos y subditos a otros lugares o ciudades [...] Y si esto es assi, con mucha mas razon seria conveniente sacar a los yndios que viven en los campos, montes e yslas desiertas, y reducirlos a poblado en villas o ciudades, para que sean instruidos mas comodamente en el estado politico y religión católica, sin que sirva de ambaraso su repugnancia, pues no se deve estar a su querer o no querer, quando la comun utilidad y conveniencia publica lo pide [...] Y es muy de la grandeza y piedad del Principe, y de la Republica Cristiana, que a los que asi repugnan sus mismas conveniencias por falta de conocimiento y discreción, obligarlos aunque no quieran, y ampararlos y conservarlos, aun contra su gusto" ${ }^{57}$.

De esta manera, el religioso mercedario concluyó en este punto que "el remedio que yo hallo para reducirlos a vida racional, es sacarlos de la ysla y ponerlos en parte donde con la comunicación y trato, assi de ministros Españoles como de curas y sacerdotes, aprehendan a vivir políticamente, pues sola esta humana policía seria bastante a que pareciessen racionales y no fieras" 58 .

En lo que respecta a la superación de los impedimentos que dificultan la evangelización, Pedro de Oro estableció su legalidad en las obligación ineludible que tenían los soberanos de España de propagar la fe en sus reinos. En consideración de los deberes reales en este campo, el sacerdote informó al gobernador su parecer de que debía "poner los medios convenientes a la doctrina y enseñanza deste gentío, por ser muy conforme al zelo de nuestro Catholico Monarca [...] Y no auiendo otro medio, sino extraerlos y transportarlos de la ysla al lugar mas acomodado a la comunicación y comercio de Ministros Evangelicos, hallo por precisso el hacerlo" 59 . La postura, como es fácil de comprobar, es radicalmente opuesta a la de los franciscanos.

Finalmente, la discusión de la última variable, el peligro de que los piratas y enemigos de España se abastecieran en la isla se asentó, en parte, sobre un supuesto igualmente distinto del planteado por los hijos de San Francisco. Recuérdese que para Fray Alonso Briceño la ayuda en bienes que los naturales brindaron a los navegantes no podía ser considerada como un fundamento legitimador del desarraigo, ya que los indios de seguro se vieron en la obligación de hacerlo ante la amenaza de los europeos. Para el mercedario, en cambio, el auxilio brindado se fundó más bien en el hecho de que "esta gente es facil, [por lo cual] ay causa de temer la confederacion de ellos con nuestros enemigos" 60 . De esta manera, la necesidad de seguridad del reino así como la naturaleza inconstante de los naturales - nuevamente se actualiza este estereotipo- se amalgaman para conformar los dos caras de una moneda que legitime la transportación de los mochanos, los que "por la cortedad de sus entendimientos, yerran muchas veces mas de ignorancia que

\footnotetext{
57 Ibídem, fs. 507-508

58 Ibídem, f. 506.

59 Ibídem, f. 510.

60 Ibídem, f. 511.
} 
de malicia" ${ }^{1}$. No desconoce Pedro de Oro que al mudarlos también se velaba por su propia seguridad, pero en la balanza de los intereses la tranquilidad del reino era el factor de mayor peso, dado que "de los dos estremos es mas racional que padescan ellos la privación y transportación de su natural, que el todo el Reyno las invasiones que se temen de Europa [...] pues el bien publico se debe preferir al particular, como tambien es precisso cortar el miembro encancerado, porque no se apodere de todo el cuerpo el cancer" 62 .

Una visión más providencialista había presentado un par de semanas antes Fray Antonio de la Cruz, prior provincial de la Orden de San Agustín. En un breve informe hacía notar que todo lo sucedido en la isla unos meses atrás había sido fruto de la intervención divina, la cual "permitió que aquellos varbaros cometiesen la traision de socorrer al pirata para que de esta culpa se originase el sacarlos de sus tierras y predicarles para que admitan nuestra Santa Fee"63. En otras palabras, fue la voluntad de Dios, interesado en que la fe se difundiese en esas almas idolátricas, la que sentó la posibilidad legal (legitimante) de intervenir en la isla dada la traición en que habían incurrido sus moradores. Sin embargo, el oportunismo del agustino se reveló con prontitud, ya que para asegurar que una vez trasladados no volviesen a la isla, ofreció al gobernador José de Garro proporcionarles tierras "en una posession donde mi communidad tiene los ganados de su sustento llamado Loncotome [...] donde se les pondran obreros del Santo Evangelio para que les prediquen y se bautisen en onrra y gloria de Dios y christiano celo de la Real Magestad"64.

En el mismo mes de septiembre de 1684 el padre Antonio Alemán, provincial de los jesuitas, ponderó al igual que los anteriores religiosos la dificultad que implicaría convertir a los indios en su propia isla, puesto que en ella "habitan como fieras, ya que los indios son gentiles y bárbaros, sin policía ni población" ${ }^{65}$. Sin pretender reiterar puntos que ya hemos tocado, el sacerdote jesuita integra breve y directamente los principales estereotipos en uso en aquella época para referirse a los indios: su incontrolada fiereza, su desapego a la verdadera fe, su carencia de orden en las costumbres y forma de vida, así como la falta de estabilidad de sus asentamientos, son epítetos que complotan para conformar un cuadro poco afortunado de quienes, en última instancia, también eran súbditos del rey. Avala la intervención real ya que el Monarca Político tiene el deber de conservar a sus vasallos en vida política para la observancia de la ley y costumbres morales a que están obligados todos los hombres, "lo cual mal se puede ejecutar sin que los hombres se reduzcan a cierto estilo de vida sociable, político y civil, estando sujetos a una cabeza que los gobierne en equidad y justicia, y todo esto se ejercita en las poblaciones de ciudades, villas o pueblos"66. La condición de sociedades acéfalas, carentes de una autoridad visible, permanente y respetada (como los reyes) era considerado como otro factor de retraso, un vértice más del barbarismo de los indios. El sometimiento a esquemas jerárquicos era un requisito sine qua non de la civilidad, en el que cada grupo o estrato ocupaba un lugar compatible con sus posibilidades naturales: así como en la naturaleza había una cadena de fieras mayores y menores, en el edificio social correspondía a cierto grupo de personas (políticos, magistrados, intelectuales) ocupar la cúspide del sistema, en tanto que el camino hacia la base se identificaba con una degradación igualmente acorde con la naturaleza espiritual y la capacidad intelectual de sus unidades constitutivas (Pagden 1988: 107-108). Por esto Antonio Alemán avaló la idea de la transportación, ya que a su entender era políticamente correcto trasladarlos a tierra firme para que se reduzcan a vida política y sociable, "propia de hombres

\footnotetext{
61 Ibídem, f. 513.

62 Ibídem, f. 512.

63 “Informe de Fray Antonio de la Cruz, prior provincial de la Orden de San Agustín, 2 de septiembre de 1684”, B.N.O.M., t. 323, f. 516.

64 Ibídem.

65 “Informe del Padre Antonio Alemán de la Compañía de Jesús, Provincial desta Provincia de Chile, sobre la transportación de los indios de la Mocha; 12 de septiembre de 1684", B.N.O.M., t. 323, f. 517.

66 Ibídem, f. 518.
} 
racionales, y esto solo se puede conseguir al haber una cabeza que los gobierne conforme a las leyes de España"67. Finalmente, el religioso invoca los deberes de la donación papal, según la cual los Reyes Católicos y sus sucesores estaban obligados a evangelizar a los gentiles. La reducción en el continente permitiría cumplir al mismo tiempo con los deberes políticos y religiosos de la Corona para con sus súbditos, por lo que la postura del padre Alemán se sustenta en un principio práctico (muy propio de los jesuitas): alcanzar los objetivos del modo más eficiente, directo y rápido posible.

No deja de llamarnos la atención que las reflexiones y propuestas de Fray Antonio Alemán parecieran ir en contra de la conocida tendencia de los jesuitas por amparar los derechos de los naturales. Sin embargo, el mismo documento revela el fuerte apoyo que tuvo este sacerdote de parte de otros correligionarios de la orden, como fue el caso de los padres Miguel de Viñas, Tomás de Gamboa, Juan de Mendoza, Ignacio Alemán, Luis de Santisteban y Esteban Santos.

Finalmente, el informe de los oidores de la Real Audiencia mostró una voluntad igualmente convergente en la transportación de los mochanos. A pesar de reconocer que se trataba de indios de paz, el hecho de que nunca hayan sido doctrinados ni enseñados en las cosas de la Santa Fe era fundamento suficiente para justificar la mudanza:

"es de advertir que aunque no devan ser compelidos directamente a rresiuir el bautismo pueden ser rremouidas por el Prinsipe todas aquellas causas que impiden la predicación del evangelio y la recepción de la Catolica Fe y si en la isla de la Mocha se a reconocido dificultad en que estos yndios puedan ser doctrinados y que en ella tengan pasto espiritual, esta con este motivo justificada su transportación a parte mas comoda"68.
A esto sumaban la ventaja que significaba desalojar la isla para impedir que las naves enemigas se abastecieran en sus costas.

\section{Conclusión}

A partir de la década de 1570 estuvo en la agenda de la Corona británica la idea de explorar y explotar tierras al sur de los dominios ibéricos en América. La exitosa circunnavegación del globo encabezada por Francis Drake en 1579, y la fracasada expedición de la Armada Invencible en 1588, dieron a Inglaterra el aliento y la llave para adentrarse en las latitudes oceánicas que hasta ese momento eran monopolio de castellanos y lusitanos. A partir de este instante, el candado que sellaba la navegación de las hasta entonces tranquilas aguas del Mar del Norte y del Mar del Sur fue roto por la intromisión de naves mejor equipadas y tripulaciones mejor entrenadas. La ondulante alfombra azul que rodeaba al continente americano dejó de ser el tapete exclusivo del mundo ibérico.

La situación de incertidumbre que se vivía en las posesiones del Pacífico meridional obligó a las autoridades a barajar alternativas drásticas que permitieran paliar tan difícil coyuntura. La seguridad del imperio primó por sobre el derecho tradicional de los indígenas de isla Mocha. El gobernante José de Garro, empeñado en eliminar un foco de inseguridad, buscó los medios jurídicos, políticos y éticos necesarios para legitimar el despueble de un sistema insular que detentaba una ocupación de más de 3 mil años. Las alternativas barajadas giraron en torno al problema de una eventual traición que nunca pudo ser probada (algunos de cuyos declarantes fueron incluso manipulados), y a los estereotipos que daban sentido, en el discurso español, a la imagen del reche-mapuche como un bárbaro, idólatra y desleal.

67 Ibídem, f. 519.

68 Informe de los Oidores al presidente en que indican la convivencia de que los indios que habitan la isla sean transportados al continente, 25 de agosto de 1684, B.N.O.M., t. 323, f. 495. 


\section{Bibliografía}

Fuentes manuscritas:

Biblioteca Nacional de Chile, Manuscritos Originales de José Toribio Medina (B.N.O.M.): 323.

Bibliografía y documentos publicados:

ARTEAGA, D. (1861), Actas del Cabildo de Santiago. Colección de Historiadores de Chile. Santiago: Imprenta del Ferrocarril, tomo 1.

BARROS ARANA, D. (2000), Historia General de Chile. Santiago: Editorial Universitaria, tomo 5.

ENCINA, F. A. (1983), Historia de Chile, Santiago: Editorial Ercilla, tomo 5.

FOUCAULT, M. (1983), Genealogía del poder. Barcelona: Editorial Crítica.

GOICOVICH, F. (2004), "Reevaluación etnohistórica de las ayllareguas reche-mapuches", Actas del V Congreso Chileno de Antropología 559-565, Sociedad Chilena de Antropología, San Felipe.

HANKE, L. (1978), Biblioteca de Autores Españoles: los Virreyes Españoles en América durante el Gobierno de la Casa de Austria (Perú), Madrid, tomos 1, 2, 3 y 5 .

JÄGER, S. (2004), “Discurso y conocimiento: aspectos teóricos y metodológicos de la crítica del discurso y del análisis de dispositivos", en Métodos de análisis crítico del discurso 61100, R. Wodack y M. Meyer (comps.), Editorial Gedisa, Barcelona.

LEÓN, L. (2000-01), “Indios, piratas y corsarios en las costas de la Araucanía y la Patagonia”, en Boletín de Historia y Geografía, Universidad Católica Raúl Silva Henríquez, Chile 15: 117-151.

LÓPEZ DE VELASCO, J. (1971), Biblioteca de Autores Españoles: Geografía y descripción universal de las Indias 1571-1574, Madrid.

MEDINA, J.T. (1928), Colección de Documentos Inéditos para la Historia de Chile (primera serie). Santiago, Imprenta Elzeviriana, tomo 28.

MEDINA, J.T. (1960), Colección de Documentos Inéditos para la Historia de Chile (segunda serie), Fondo Histórico y Bibliográfico José Toribio Medina, Santiago, tomo 4.

MEDINA, J.T. (1961), Colección de Documentos Inéditos para la Historia de Chile (segunda serie), Fondo Histórico y Bibliográfico José Toribio Medina, Santiago, tomo 5.

OCAÑA, D. (1995), Viaje a Chile: Relación del viaje a Chile, año de 1600, contenida en la crónica de viaje intitulada "A través de la América del Sur” 1607. Santiago: Editorial Universitaria.

PAGDEN, A. (1988), La caída del Hombre Natural. El indio americano y los orígenes de la etnología comparativa. Madrid: Alianza Editorial.

STEWART, H. (2000), Del Mar del Norte al Mar del Sur. Navegantes británicos y holandeses en el Pacífico suroriental, 1570-1807. Valparaíso: Editorial Puntángeles.

WODAK, R. (2003), "De qué trata el análisis crítico del discurso (ACD). Resumen de su historia, sus conceptos y sus desarrollos", en Métodos de análisis crítico del discurso 17-34, R. Wodack y M. Meyer (comps.). Barcelona: Editorial Gedisa. 